\title{
EFEITO DE DIFERENTES ARRANJOS NO CONSÓRCIO MILHO-FEIJÃO E MILHO-CAUPI NO ACRE, BRASIL
}

\author{
João Gomes da COSTA' ${ }^{1}$, José Tadeu de Souza MARINHO'
}

\begin{abstract}
RESUMO - Visando estudar um sistema de cultivo para o consórcio do milho (Zea mays L.) com feijão (Phaseolus vulgaris L.) e milho com o caupi (Vigna unguiculata (L.) Walp), foram conduzidos experimentos durante os anos de 1995 e 1996, em Rio Branco, Acre. Quatro diferentes arranjos (uma, três, cinco e sete fileiras de feijão ou caupi para uma fileira de milho) foram testados no delineamento de blocos ao acaso com quatro repetições. A produtividade do feijão e do caupi, no arranjo de linhas $1: 1$, foi significativamente inferior aos demais, evidenciando que as leguminosas foram afetadas pela competição com milho. A produtividade do milho decresceu linearmente de acordo com o arranjo, devido as menores populações de plantas utilizadas. $\mathrm{O}$ sistema consorciado mais promissor, demonstrado pela produção equivalente, foi o arranjo composto por uma fileira de milho para três fileiras das leguminosas.
\end{abstract}

Palavras-chave: Zea mays, Phaseolus vulgaris, Vigna unguiculata, sistema de plantio.

Effect of Different Arrangements on Maize-Common Bean and Maize-Cowpea Mixtures in Acre State, Brazil

ABSTRACT - To study the arrangement of mixtures of maize (Zea mays L.) with beans (Phaseolus vulgaris L.) or cowpea (Vigna unguiculata (L.) Walp), mixed cropping experiments were planted in 1995 and 1996, in Rio Branco, Acre. Four different arrangements (one, three, five, seven rows of beans or cowpea:one row maize) were tested in a randomized block design with four replications. The productivity of the beans and the cowpea in the 1:1 arrangement proved to be significantly inferior to the others, showing that the legumes were effected by the competition with the maize. The productivity of the maize decreased linearly in accordance with the arrangement owing to lower population densities. The most promising mixture, demonstrated by equivalent productivity, was composed of a row of maize to three rows of legumes.

Key-words: Zea mays, Phaseolus vulgaris, Vigna unguiculata, planting systems.

\section{INTRODUÇÃO}

A prática da consorciação envolvendo culturas de subsistência é tradicional e amplamente utilizada por pequenos agricultores. Dentre os principais fatores que determinam a utilização deste sistema de produção, destacam-se a redução dos riscos de perdas, o uso mais eficiente da terra e maior retorno econômico (Lima et al., 1987; Portes, 1996). No Estado do Acre, a associação envolvendo as culturas do milho com feijão e caupi, limita-se a plantios em áreas de várzeas no periodo de março a maio, ocasião em que os rios diminuem o volume de suas águas. Nas áreas de terra firme, predomina o cultivo do milho, cujo plantio é realizado entre a segunda quinzena de setembro até o final de outubro, com o feijão plantado em sucessão à gramínea (final de março até maio). Nestas condições, o milho pode ser colhido ou simplesmente dobrado para servir 
como suporte ao feijão. Ocorrem casos isolados onde o consórcio simultâneo é realizado em áreas de terra firme, cuja finalidade principal é o consumo do milho verde. A partir da recomendação, pela Embrapa Acre, de materiais de milho precoces para o Estado, tornou-se possível aos agricultores a realização de plantios simultâneos destas culturas, com a finalidade de permitir maior sustentação e rentabilidade ao sistema produtivo.

A cultura do feijão, no Estado do Acre, normalmente apresenta sérios problemas fitossanitários como a incidência da mela do feijoeiro (Thanatephorus cucumeris, (Frank) Donk) e da vaquinha (Cerotoma tingomarianus, Bechyné), tornando-se uma cultura de risco para os agricultores. Assim, com a utilização da consorciação entre culturas, o risco de perdas da produção total é reduzida.

Os arranjos e as populações de plantas usadas no consórcio são bastante variáveis. Siqueira \& Sobral (1979) concluíram que, para Sergipe, o ideal seria o plantio de três linhas de feijão entre as linhas de milho, espaçamento entre linhas de 2,0 m (milho) e $0,5 \mathrm{~m}$ (feijão), resultando numa população de 15.000 e 150.000 plantas/ha para milho e feijão , respectivamente. Já Vieira et al. (1980) concluíram que uma fileira de milho para duas de feijão e uma de milho para três de feijão foram os arranjos mais eficientes. Vários ensaios desenvolvidos por Rao \&
Morgado (1984), no nordeste brasileiro, concluíram que os consórcios milho e feijão e milho e caupi superaram os monocultivos em 32 e $41 \%$, respectivamente, e que os melhores arranjos foram aqueles compostos por uma fileira de milho para três de feijão e uma de milho para duas de caupi.

Portanto, torna-se necessária a definição de arranjos ideais para estas culturas no Estado do Acre, tendo em vista que os agricultores utilizam os mais variados arranjos espaciais.

\section{MATERIAL E MÉTODOS}

Foram desenvolvidos dois experimentos envolvendo os consórcios entre milho-caupi e milhofeijão, durante os anos de 1995 e 1996, no Campo Experimental da Embrapa Acre. Utilizaram-se as cultivares BR 5133 (milho super precoce), Carioquinha (feijão) e Rio Branco (caupi). Para ambos os experimentos foi utilizado o delineamento de blocos ao acaso com quatro repetições. Foram testados quatro arranjos de plantas em cada experimento, com plantio simultâneo do milho, caupi e feijão. Os arranjos de plantas foram os seguintes:

Arranjo A - uma fileira de feijão ou caupi entre duas fileiras de milho, com o espaçamento de $1,00 \mathrm{~m}$ x 0,40 $\mathrm{m}$ e $1,00 \mathrm{~m} \times 0,30 \mathrm{~m}$ para milho e feijão ou caupi, respectivamente.

Arranjo B - três fileiras de feijão ou caupi entre duas fileiras de milho, com o espaçamento de $2,00 \mathrm{~m}$ 
x $0,40 \mathrm{~m} \mathrm{e} 0,50 \mathrm{~m} \times 0,30 \mathrm{~m}$ para milho e feijão ou caupi, respectivamente.

Arranjo C - cinco fileiras de feijão ou caupi entre duas fileiras de milho, com espaçamento de $3,00 \mathrm{~m}$ $\mathrm{x} 0,40 \mathrm{~m}$ e $0,50 \mathrm{~m} \times 0,30 \mathrm{~m}$ para milho e feijão ou caupi, respectivamente.

Arranjo D - sete fileiras de feijão ou caupi entre duas fileiras de milho, com espaçamento de $4,00 \mathrm{~m} \mathrm{x}$ $0,40 \mathrm{~m}$ e $0,50 \mathrm{~m} \times 0,30 \mathrm{~m}$ para milho e feijão ou caupi, respectivamente.

As parcelas dos diferentes arranjos foram compostas por linhas de $5 \mathrm{~m}$ de comprimento eliminandose $0,50 \mathrm{~m}$ nas extremidades para efeito de avaliação.

Foram avaliadas a produtividade de grãos ( $\mathrm{kg} / \mathrm{ha})$ das culturas envolvidas e a análise conjunta da produção de grãos foi calculada pela estimativa da produção equivalente de milho, obtida pela metodologia apresentada por Ramalho et al. (1983), de acordo com a seguinte expressão: $\mathrm{Ye}=\mathrm{Ym}+\mathrm{rYc}$ (ou rYf) onde, Ye é a produção equivalente de milho; Ym, Yc, Yf são a produção de grãos de milho, caupi e feijão ( $\mathrm{kg} / \mathrm{ha})$, respectivamente; r é a relação entre o preço do caupi ou feijão e do milho. No presente caso, tomou-se o valor de $\mathrm{r}$ igual a 4,01, que corresponde à média observada no Acre, entre 1993 e 1996.

\section{RESULTADOS E DISCUSSÃO}

\section{Experimento 1 - Consórcio milho e caupi}

Verificou-se que houve diferença significativa entre os arranjos para os caracteres avaliados (Tab. 1). Os arranjos B e D proporcionaram os maiores rendimentos para o caupi. O arranjo A proporcionou menor rendimento para a leguminosa mostrando uma forte competição exercida pelo milho. Entretanto, na média geral, o consórcio mostrou rendimento superior a média estadual desta leguminosa (em torno de $500 \mathrm{~kg} / \mathrm{ha}$ ).

Com relação ao milho verificase que houve um decréscimo linear da produção de acordo com o arranjo (Tabela 1). Isto se explica devido as diferentes populações de milho utilizadas. Assim, constatou-se que o maior rendimento foi proporcionado pelo arranjo A, que foi composto pelo mesmo número de plantas comumente utilizado no monocultivo $(50.000$ plantas por hectare). Verifica-se também, que, na média geral, o rendimento médio do consórcio (2.089 $\mathrm{kg} / \mathrm{ha}$ ) superou a média estadual de milho $(1.500 \mathrm{~kg} / \mathrm{ha})$. Este fato indica que o milho praticamente não foi afetado pelo caupi, estando de acordo com os resultados obtidos por Cardoso et al. (1994).

A produção equivalente de milho, isto é, a produção combinada do milho mais caupi em função da relação de preços das duas culturas, mostrou diferença significativa entre os efeitos dos arranjos. O arranjo B foi o que proporcionou maior rendimento, mostrando que a combinação ideal é aquela formada pela maior produção do caupi com a segunda maior da cultura do milho. Outra situação 
Iabeia 1. Valores médios de dois anos agrícolas da produção de grãos de caupi e milho em consórcio e produção equivalente de milho (PEQUIV), em kg/ha.

\begin{tabular}{cccc}
\hline TRATAMENTOS & CAUPI & MLHO & PEQUN. \\
\hline Arranjo A & $1014 \mathrm{~b}$ & $3746 \mathrm{a}$ & $7813 \mathrm{ab}$ \\
Arranjo B & $1661 \mathrm{a}$ & $2269 \mathrm{~b}$ & $8929 \mathrm{a}$ \\
Arranjo C & $1364 \mathrm{ab}$ & $1351 \mathrm{bc}$ & $6822 \mathrm{~b}$ \\
Arranjo D & $1444 \mathrm{a}$ & $990 \mathrm{c}$ & $6782 \mathrm{~b}$ \\
\hline Média & 1371 & 2089 & 7586 \\
C.V. (\%) & 22,10 & 40,96 & 23,64 \\
\hline
\end{tabular}

Médias seguidas de letras iguais na mesma coluna náo diferem significativamente pelo teste de Tukey a $5 \%$ de probabilidade.

-Arranjo A (uma fileira de caupi entre duas fileiras de milho); Arranjo B (três fileiras de caupi entre duas fileiras de milho); Arranjo C (cinco fileiras de caupi entre duas fileiras de milho); Arranjo D (sete fileiras de caupi entre duas fileiras de milho).

favorável é o arranjo A, onde a menor produção do caupi é compensada pela maior produção do milho. Comparando-se o arranjo D, que proporcionou a menor média para produção equivalente $(6782 \mathrm{~kg} / \mathrm{ha})$ com o arranjo $\mathrm{A}$, que a apresentou a maior média para o milho $(3746 \mathrm{~kg} /$ ha), verifica-se que o consórcio superou o plantio isolado em $81 \%$.

Diversos trabalhos mostraram que o milho praticamente não é afetado quando consorciado com feijão ou caupi, principalmente quando a sua densidade de plantio é semelhante à do monocultivo; entretanto, há relatos de redução na produtividade da gramínea (Andrade et al., 1974; Santa Cecilia \& Vieira, 1978; Aidar et al., 1979; Reis, 1984; Cruz et al., 1987; Pereira Filho et al., 1991). Lima et al., 1987, concluíram que a presença do feijoeiro, independente da densidade de plantas estudadas, não afetou o milho.

\section{Experimento 2 - Consórcio milho e feijão}

Verifica-se que houve diferenças entre os arranjos para a produção do feijão (Tab. 2). No arranjo $A$, o feijão foi prejudicado pela competição com a cultura do milho. Os demais arranjos não apresentaram diferenças significativas. Estes resultados estão de acordo com os de Pereira Filho et al. (1991), que concluíram que o aumento na densidade de plantas de milho reduziu linearmente a produtividade do feijoeiro.

Com relação ao milho, verificase que houve um desempenho semelhante quando consorciado com o caupi. Houve decréscimo linear da 
Tabela 2. Valores médios de dois anos agrícolas da produção de grãos de feijão e milho em consórcio e produção equivalente de milho (PEQUIV), em kg/ha.

\begin{tabular}{cccc}
\hline TRATAMENTOS & FENÃO & MLHO & PEQUN. \\
\hline Arranjo A & $954 \mathrm{~b}$ & $2859 \mathrm{a}$ & $6680 \mathrm{~b}$ \\
Arranjo B & $1443 \mathrm{a}$ & $1606 \mathrm{~b}$ & $7919 \mathrm{a}$ \\
Arranjo C & $1390 \mathrm{a}$ & $1435 \mathrm{~b}$ & $6848 \mathrm{ab}$ \\
Arranjo D & $1505 \mathrm{a}$ & $1047 \mathrm{~b}$ & $7084 \mathrm{ab}$ \\
\hline Média & 1323 & 1737 & 7133 \\
C.V. (\%) & 17,70 & 29,40 & 14,50 \\
\hline
\end{tabular}

Médias seguidas de letras iguais na mesma coluna não diferem significativamente pelo teste de Tukey a $5 \%$ de probabilidade.

*Arranjo A (uma fileira de feijăo entre duas fileiras de milho); Arranjo B (três fileiras de feijâo entre uas fileiras de milho); Arranjo C (cinco fileiras de feijẫo entre duas fileiras de milho); Arranjo D (sete ileiras de feijẫo entre duas fileiras de milho).

produção de acordo com o arranjo. Assim, constatou-se que o maior rendimento foi proporcionado pelo arranjo $\mathrm{A}$, que foi composto pelo mesmo número de plantas comumente utilizado no monocultivo (50.000 plantas por hectare). Na média geral, o rendimento médio do consórcio (1.737 kg/ha) superou a média estadual de milho $(1.500 \mathrm{~kg} / \mathrm{ha})$. Lima et al., 1987, concluíram que a presença do feijoeiro, independente da densidade de plantas estudadas, não afetou o milho.

A produção equivalente de milho, isto é, a produção combinada do milho mais feijão em função da relação de preços das duas culturas, apresentou diferença significativa entre os efeitos dos arranjos. O arranjo $B$ foi o que proporcionou maior rendimento, sendo a combinação ideal aquela formada pela maior produção do feijão com a segunda maior da cultura do milho, concordando com os resultados de Siqueira \& Sobral (1979), Vieira et al. (1980) e Rao \& Morgado (1984). O alto risco na produção do feijão na região, devido ao ataque de pragas e doenças, é a principal desvantagem do monocultivo em relação ao consórcio, o qual propicia melhor uso da terra, melhor controle da erosão, diversificação da dieta alimentar, maior renda bruta e maior estabilidade na produção.

\section{CONCLUSÕES}

A produtividade de grãos do feijão e do caupi foi afetada pela competição exercida pela cultura do milho no arranjo composto por uma 
fileira de milho para uma de feijão ou caupi. A produção equivalente mostrou que $o$ arranjo composto por uma fileira de milho para três fileiras das leguminosas foi o mais promissor, podendo ser recomendado para uso no Acre para se obter melhor renda.

\section{Bibliografia citada}

Aidar, H.; Vieira, C.; Oliveira, L.M.; Vieira, M. 1979. Cultura associada de feijão e milho. II. Efeitos de populações em plantio simultâneo de ambas as culturas. Revista Ceres, 26(143):102-111.

Andrade, M.A.; Ramalho, M.A.P.; Andrade, M.J.B. 1974. Consorciação de feijoeiro (Phaseolus vulgaris L.) com cultivares de milho (Zea mays L.) de porte diferente. Agros, 4(2):23-30.

Cardoso, M.J.; Freire Filho, F.R.; Ribeiro, V.Q.; Frota, A.B.; Melo, F.B. 1994. Arranjo populacional no consórcio milho $\mathrm{x}$ feijão macassar (Vigna unguiculata (L.) Walp.) em regime de sequeiro. Revista Ceres, 41(233):19-27.

Cruz, J.C.; Ramalho, M.A.P.; Salles, L.T.G. 1987. Utilização de cultivares de milho prolifico no consórcio milho-feijão. Pesquisa Agropecuária Brasileira, 22(2):203-211.

Lima, J.M.P.; Lima, L.A.P.; Andrade, L.A.; Rezende, P.M. 1987. Influência de diferentes populações e da adubação no sistema consorciado milho e feijão. Pesquisa Agropecuária Brasileira, 22(8):817-823.

Pereira Filho, I.A.; Cruz, J.C.; Ramalho, M.A.P. 1991. Produtividade e indice de espiga de três cultivares de milho em sistema de consórcio com o feijão-comum. Pesquisa Agropecuária Brasileira, 26(5):745-751.
Portes, T.A. 1996. Produção de feijão nos sistemas consorciados. (Embrapa-CNPAF. Documentos, 71). Embrapa-CNPAF-APA, Goiânia. 50p.

Ramalho, M.A.P; Oliveira, A.C.; Garcia, J.C. 1983. Recomendações para o planejamento e análise de experimentos com as culturas de milho e feijão consorciadas. (Embrapa-CNPAF. Documentos, 71). Embrapa-CNPMS. Sete Lagoas. 74p.

Rao, M.R.; Morgado, L.B. 1984. A review of maize-beans e maize-cowpea intercrop systems in the semiarid Northeast Brasil. Pesquisa Agropecuária Brasileira, 19(2):179-192.

Reis, W.P. 1984. Análise de crescimento de milho e feijão em monocultivo $e$ consorciado em diferentes arranjos da semeadura destes cultivos. Dissertação de Mestrado, ESAL. Lavras, MG. 113p.

Santa Cecília, F.C.; Vieira, C. 1978. Associated cropping of beans and maize. I. Effects of bean cultivars with different growth habit. Turrialba, 28(1):19-23.

Siqueira, L.A.; Sobral, L.F. 1979. Arranjos e populações de plantas de milho e feijão no sistema consorciado em Sergipe. (Embrapa-Uepae de Quissamã. Comunicado Técnico, 2). Embrapa-Uepae de Quissamã, Quissamã - SE. 6p.

Vieira, S.A; Ben, J.R.; Gastal, F.L.C. 1980. Avaliação do cultivo do milho e feijão nos sistemas exclusivo e consorciado. Pesquisa Agropecuária Brasileira, 15(1):19-26. 